\title{
Hearing loss in patients with oral cavity tumours treated with radiation and chemoradiation
}

\author{
Raghu Raman $\mathbf{R}^{1, *}$ and Sreekanth $\mathbf{G}^{2}$ \\ ${ }^{1}$ Department of Radiation Oncology, MNJ Institute of Oncology \& Regional Cancer Centre, Hyderabad, Telangana, India \\ ${ }^{2}$ Department of ENT, Gandhi Medical College, Hyderabad, Telangana, India
}

\begin{abstract}
Aim: To analyze and report the short term sensorineural hearing loss with radiation alone and chemoradiation in patients with oral cavity tumours (Ca tongue and Ca Buccal mucosa) treated with conventional radical radiotherapy and concurrent weekly cisplatin.

Materials and methods: 30 patients with oral cavity squamous cell carcinomas were subjected to 66Gy radiation as radical or adjuvant treatment. Early lesions were operated and received RT only. T3 \& T4 lesions underwent chemoradiation with weekly concurrent cisplatin @ 40mg $/ \mathrm{m}^{2}$. Among the 16 tongue patients 6 were postoperative and among the $14 \mathrm{BM}$ patients 6 were postoperative. The middle ear and cochlea were contoured and mean doses calculated in 60 ears. Pure tone audiometry was performed as baseline before treatment, at 90 days and 180 days.
\end{abstract}

Results: The doses received between the 2 groups and the hearing loss in $\mathrm{dB}$ was compared. There were no significant difference in doses in all the ears except the ipsilateral and contra lateral ear of the BM patients. The mean chemotherapy doses were similar in both arms $(\mathrm{p}=0.4085)$. The 90 days and 180 s day mean hearing loss was significant in all the groups with RT alone and chemoRT. There was no difference in the HL in the ChemoRT group of tongue and BM at 90 days $(\mathrm{p}=0.1592)$ and 180 days $(\mathrm{p}=0.4153)$.

Discussion: The sensorineural hearing loss (SNHL) in patients who receive RT or chemoRT even at moderate doses is progressive, but is mostly mild or moderate.

Conclusions: Changing collimation may change doses to the auditory apparatus. HL was progressive in both tongue \& BM groups. RT doses of $66 \mathrm{GY} \pm$ cisplatin @ $40 \mathrm{mg} / \mathrm{m}^{2}$ leads to mild HR in $60 \%$ patients and moderate HR in $18.4 \%$.

Keywords: Hearing loss; oral cavity tumours; radiation; chemoradiation

*Corresponding author: Dr. R Raghu Raman, Associate Professor, MNJ Institute of Oncology \& Regional Cancer Centre, Red Hills, Lakadikapul, Hyderabad-500004, Telangana, India. Email: raghuraman3008@gmail.com

Received 03 April 2018; Revised 29 May 2018; Accepted 11 June 2018; Published 19 June 2018

Citation: Raman RR, Sreekanth G. Hearing loss in patients with oral cavity tumours treated with radiation and chemoradiation. J
Med Sci Res. 2018; 6(3): 80-85. DOI: http://dx.doi.org/10.17727/ JMSR.2018/6-14

Copyright: (C) 2018 Raman RR etal. Published by KIMS Foundation and Research Center. This is an open-access article distributed under the terms of the Creative Commons Attribution License, which permits unrestricted use, distribution, and reproduction in any medium, provided the original author and source are credited. 


\section{Introduction}

Oral cancer is the most common cancer in India amongst men $(11.28 \%$ of all cancers), the fifth most frequently occurring cancer amongst women ( $4.3 \%$ of all cancers) and the third most frequently occurring cancer in India amongst both men and women [1]. The higher incidence in the Indian population is probably attributed to the higher incidence of tobacco chewing and Gutka. Gutka is a complex preparation made from crushed areca nut, tobacco, catechu, paraffin wax, slaked lime and flavoured with savours traditional to India [2, 3]. The clinical observation amongst Indian oncologists is that Gutka may cause cancer earlier than tobacco chewing and may be more aggressive. The standard of care for early oral malignancies is surgery \pm adjuvant radiation and in locally advanced lesions it is chemoradiation [4]. The hearing threshold reduces incrementally with increasing RT dose. Some studies have predicted significant hearing loss (HL) with doses of 40Gy to cochlea with RT alone. When concurrent cisplatin was used, the threshold dose may drop to as low as 10Gy [5]. The QUANTEC review suggests a tolerance dose of $\leq 45 \mathrm{~Gy}$ for the cochlea with standard fractionation $[6,7]$ which leads to approximate $\leq 15 \%$ SNHL. Chemoradiation is the present standard of care for locally advanced lesions [4]. However chemoradiation enhances toxicity at the cost of improved OS and PFS [8-10]. The hearing loss associated with radiation is generally of lower frequencies and tends to progress with time. Hearing loss is quantified in decibel units and classified based on decibel loss as follows: mild - 26-40(dB) moderate41-55(dB) severe 56-70 $(\mathrm{dB})$ profound 71$9(\mathrm{~dB})$ and deaf ear $>91(\mathrm{~dB})$ [11]. Borsanyi et al. and Leach demonstrated that radiotherapy has a direct effect on the sensory epithelium and alters the vascular physiology of the cochlea by damaging its ciliated cells and the spiral ganglion leading to atrophy and SNHL [12-14]. Hearing loss can be a major handicap amongst elderly people treated for head and neck cancer. Hearing loss has multifaceted psycho social effects on individuals, ranging from loneliness, depression, anger, anxiety to even suicide and decreases the QOL.

Inclusion and exclusion criteria: 1) Only oral cavity tumours were included (Ca Tongue and Ca Buccal mucosa). Other regions like larynx and nasopharynx were excluded from the study. 2) Only confirmed squamous cell carcinomas were included, all tumours other than this histology were excluded. 3) Cheek and tongue malignancies that were either locally advanced, inoperable and due for chemoradiation or operated malignancies due for adjuvant radiation. 4) Buccal mucosa with infratemporal extension was excluded as the auditory apparatus cannot be shielded. 5) All patients who reported past hearing loss or ear surgery or CSOM were excluded. 6) All patients who received prior neoadjuvant chemotherapy were excluded.

To analyze and report the short term sensorineural hearing loss with radiation alone and chemoradiation in patients with oral cavity tumours (Ca tongue and Ca Buccal mucosa) treated with conventional radical radiotherapy and concurrent weekly cisplatin.

\section{Materials and methods}

A cohort of 30 patients which included 26 male and 4 female were treated with a curative intent at Medwin hospital, Hyderabad from May 2015 to October 2016. All the patients had either locally advanced tumours i.e., T3 or T4 lesions with N0, N1, N2 or N3 status or underwent surgery for $\mathrm{T} 1$ or $\mathrm{T} 2$ lesions with No or N1 status. Among the 16 tongue five underwent hemiglossectomy and ipsilateral MRND for early disease. Among the 14 BM patients six underwent composite resection for early disease.

All the patients received a dose of 66Gy/33\# @ 2 Gy/day as part of the radiation treatment. Postoperative patients also received $66 \mathrm{~Gy} / 33$ \# instead of $60 \mathrm{~Gy} / 30 \#$ due to the high recurrence rates observed in the tobacco and gutka chewing populations of India. All patients completed the course of radiation from 6.5 to 9 weeks. All locally advanced patients received concurrent weekly cisplatin @ 40mg/m² per week. None of the patients received neoadjuvant or adjuvant cisplatin.

Radiation planning was done using CT simulation, thermoplastic mask and I/V contrast with Oncentra 2.6 software version 4 with a Siemens Linear Accelerator using collapsed cone and pencil beam iteration systems. With a $90^{\circ}$ collimation, the average doses could be reduced by $4.6 \%$ in ipsilateral ear and $2.1 \%$ in contra lateral ear in BM patients and $5.6 \%$ in tongue patients and hence preferred to the $0^{\circ}$ collimation. The patients were treated as per the standard protocols mentioned in standard text books like Gunderson \& Tepper [15] and Perez 
\& Brady [16]. The upper field was adjusted to the base of the skull to include the retropharyngeal nodes. The 90 degree collimation gave the degree of freedom to shield the EAM and cochlea without compromising on the retropharyngeal nodal doses. Patients with Ca tongue received only scattered doses. The $90^{\circ}$ collimation also permitted the use of dynamic wedges. The anterior field could not be shielded in BM patients as it overlapped with the target volume. The $90^{\circ}$ collimation helped in better shielding of the brain stem and better coverage of posterior cervical nodes and retropharyngeal nodes as $\mathrm{C} 1$ vertebra was below it and the skull base had a concave shape at that level.

Tongue patients received parallel opposed fields with the upper border placed $2 \mathrm{~cm}$ superior to the mouth-bite or base of skull and a lower field to cover level 4, 5 and 6 nodes. Among the 16 patients, 7 had the upper border above the EAM. All the MLCs were $\geq 1 \mathrm{~cm}$ from the CTV. The BM patients received anterolateral fields and similar ipsilateral lower fields. The MLCs were $\leq 7 \mathrm{~mm}$ from the contoured CTV. The upper border was at the zygoma and happened to be above the EAM in 13 out of the 14 BM patients. Perpendicular wedges were used for BM planning with occasion field in field. Mean doses to the ME and cochlea were derived from the dose distribution table as DVH could not be generated due to low volume ME and cochlea. The final doses to ME \& cochlea was the mean of the left and right ear as the tongue was a central organ unlike buccal mucosa which was ipsilateral. The Oncentra 2.6 software version 4 was capable of generating only isodose curves and not a colour wash like in the present iteration systems and hence only mean doses could be determined in small volume OAR's.

All the patients underwent a pure tone audiometry at the Department of ENT at Gandhi Hospital from May 2015 to Dec 2016. Audiometry was performed just before the start of radiation, 90 days after the initiation of radiation and 180 days after the initiation of radiation and was done in a sound proof audiometer booth with masking, when indicated. Both air $(250 \mathrm{~Hz}-8000 \mathrm{~Hz})$ and bone $(500 \mathrm{~Hz}-8000 \mathrm{~Hz})$ conduction curves were obtained. The PTA done at the start served as control.

\section{Results}

All the patients completed the course of 66Gy/33\#. Cisplatin dose was altered and treatment breaks were given to ensure that the prescribed radical dose was received.18 patients received ChemoRT@ $40 \mathrm{mg} / \mathrm{m}^{2}$ (tongue $\mathrm{n}=10$; mean $204 \mathrm{mg} / \mathrm{m}^{2}, \mathrm{BM}$ $\mathrm{n}=8$; mean $185 \mathrm{mg} / \mathrm{m}^{2}$ ) which was statistically insignificant $p=0.4085$. The hearing loss for 60 ears ranged between $20-52 \mathrm{~dB}$ at 180 days follow up. Accordingly the HL at 180 days follow up was: nil$13(21.6 \%)$, mild- 36 (60\%), moderate-11(18.4\%) and severe -0 .

The data showed that there were no statistical differences in the doses received by the ME or cochlea in both ears in tongue patients and they received only scattered doses (Table 1). There was a significant difference in ipsilateral and contra lateral doses in BM (494.54cGy \pm 49.85 Vs $3018.39 \pm$ 108.07), $p=0.0001$ (Table 1 ). All the tongue patients who received RT or chemoRT had significant changes in hearing loss at 90 and 180 days (Tables $1 \& 2$ ).

Table 1: Comparison of doses and HL in tongue and BM - p values.

\begin{tabular}{|c|c|c|}
\hline \multicolumn{3}{|c|}{ Tongue } \\
\hline \multirow[t]{5}{*}{ Doses } & Parameter & $\mathrm{p}$ value \\
\hline & L Vs R Middle ear & 0.3299 \\
\hline & L Vs R cochlea & 0.1651 \\
\hline & L Middle ear Vs L cochlea & 0.2822 \\
\hline & R ME Vs R cochlea & 0.2123 \\
\hline \multirow[t]{6}{*}{ HL } & left ears 90 days $n=16$ & 0.0143 \\
\hline & Right ears 90 days $n=16$ & 0.0001 \\
\hline & Left ears 90 Vs 180 days $n=16$ & 0.0134 \\
\hline & Right ears 90 Vs 180 days $n=16$ & 0.0093 \\
\hline & Chemo RT Vs RT 90 days & 0.001 \\
\hline & Chemo RT Vs RT 180 days & 0.002 \\
\hline \multicolumn{3}{|c|}{ BM - unpaired $t$ test } \\
\hline \multirow[t]{5}{*}{ Doses } & Parameter & $\mathrm{p}$ value \\
\hline & Ipsilateral ME Vs Cochlea & 0.2146 \\
\hline & Contra lateral ME Vs cochlea & 0.0374 \\
\hline & Ipsilateral Vs contra lateral ME & $<0.0001$ \\
\hline & Ipsilateral Vs Contralat cochlea & $<0.0001$ \\
\hline \multirow[t]{6}{*}{ HL } & ipsilateral base Vs 90 days & 0.001 \\
\hline & ipsilateral 90 Vs 180 days & 0.0373 \\
\hline & contra lateral base Vs 90 days & 0.0001 \\
\hline & contra lateral 90 Vs 180 days & 0.0185 \\
\hline & BM Vs Tongue chemoRT 90d & 0.1592 \\
\hline & BM Vs Tongue chemoRT 180d & 0.4153 \\
\hline
\end{tabular}


Similarly all the patients with BM tumours had significant worsening of hearing in ipsilateral and contra lateral ears with RT and ChemoRT (Figure 2). There were no significant differences in the tongue (Figure 1) and BM groups (Figure 2) in the ChemoRT or RT arms although one side of the BM received significantly higher doses of RT and had higher mean HR $(35.25 \pm 7.02$ Vs $37.75 \pm 7.72)$ (Tables $1 \& 3$ ). The patients who received RT alone developed SNHL for higher frequencies rather than lower frequencies. In the patients receiving chemoradiation the SNHL was earlier and of mixed frequency.

Table 2: HL in $\mathrm{dB}$ among 60 assessable ears.

\begin{tabular}{|c|c|}
\hline Tongue at $90 \mathrm{~d}(19-35 \mathrm{~dB})(\mathrm{n}=30)$ & $26.43 \pm 3.57$ \\
\hline Tongue at $180 \mathrm{~d}(23-52 \mathrm{~dB})(\mathrm{n}=30)$ & $31.84 \pm 7.24$ \\
\hline $\begin{array}{l}\text { Tongue RT alone } 90 \text { days } \\
(19-29 d B)(n=12)\end{array}$ & $23.50 \pm 2.67$ \\
\hline $\begin{array}{l}\text { Tongue ChemoRT } 90 \text { days } \\
(20-35 d B)(n=20)\end{array}$ & $27.80 \pm 3.36$ \\
\hline $\begin{array}{l}\text { Tongue RT alone } 90 \text { days } \\
(22-30 \mathrm{~dB})(\mathrm{n}=12)\end{array}$ & $26.16 \pm 2.51$ \\
\hline $\begin{array}{l}\text { Tongue ChemoRT } 180 \text { days } \\
(27-52 d B)(n=20)\end{array}$ & $35.25 \pm 7.02$ \\
\hline $\begin{array}{l}\text { BM ipsilateral } 90 \text { days all patients } \\
(22-36 \mathrm{~dB})(\mathrm{n}=14)\end{array}$ & $27.46 \pm 4.25$ \\
\hline $\begin{array}{l}\text { BM contra lateral } 90 \text { days all patients } \\
(20-28 d B)(n=14)\end{array}$ & $23.21 \pm 2.58$ \\
\hline $\begin{array}{l}\text { BM Ipsilateral } 180 \text { days all patients } \\
(24-48 d B)(n=14)\end{array}$ & $32.79 \pm 8.29$ \\
\hline $\begin{array}{l}\text { BM contra lateral } 180 \text { days all patients } \\
(21-35 d B)(n=14)\end{array}$ & $26.93 \pm 4.89$ \\
\hline $\begin{array}{l}\text { BM Ipsilateral } 90 \text { days ChemoRT } \\
(27-36 \mathrm{~dB})(\mathrm{n}=8)\end{array}$ & $30.00 \pm 3.34$ \\
\hline $\begin{array}{l}\text { BM ipsilateral } 180 \text { days ChemoRT } \\
(29-48 d B)(n=8)\end{array}$ & $37.75 \pm 7.72$ \\
\hline $\begin{array}{l}\text { BM contra lateral } 90 \text { days ChemoRT } \\
(21-28 d B)(n=8)\end{array}$ & $24.63 \pm 2.33$ \\
\hline $\begin{array}{l}\text { BM contra lateral } 180 \text { days ChemoRT } \\
(22-35 d B)(n=8)\end{array}$ & $29.25 \pm 5.12$ \\
\hline $\begin{array}{l}\text { BM ipsilateral } 90 \text { days RT alone } \\
(22-26 \mathrm{~dB})(n=6)\end{array}$ & $24.00 \pm 1.41$ \\
\hline $\begin{array}{l}\text { BM ipsilateral } 180 \text { days RT alone } \\
(24-28 d B)(n=6)\end{array}$ & $26.17 \pm 1.83$ \\
\hline $\begin{array}{l}\text { BM contra lateral } 90 \text { days RT alone } \\
(21-33 d B)(n=6)\end{array}$ & $21.33 \pm 1.51$ \\
\hline $\begin{array}{l}\text { BM contra lateral } 180 \text { days RT alone } \\
(21-27 d B)(n=6)\end{array}$ & $23.83 \pm 2.32)$ \\
\hline
\end{tabular}

Table 3: Mean doses of the organs at risk (OAR) in cGY.

\begin{tabular}{|lcc|}
\hline OAR & Tongue & $B M$ \\
\hline Left middle ear & 469.93 & 2138.57 \\
Right middle ear & 488.06 & 1239.35 \\
Left Cochlea & 491.50 & 2278.78 \\
Right Cochlea & 465.18 & 1189.84 \\
Ipsilateral ME & NA & 3044.14 \\
Ipsilateral Cochlea & NA & 2992.64 \\
Contra lateral ME & NA & 513.78 \\
Contra lateral cochlea & NA & 475.28 \\
\hline
\end{tabular}
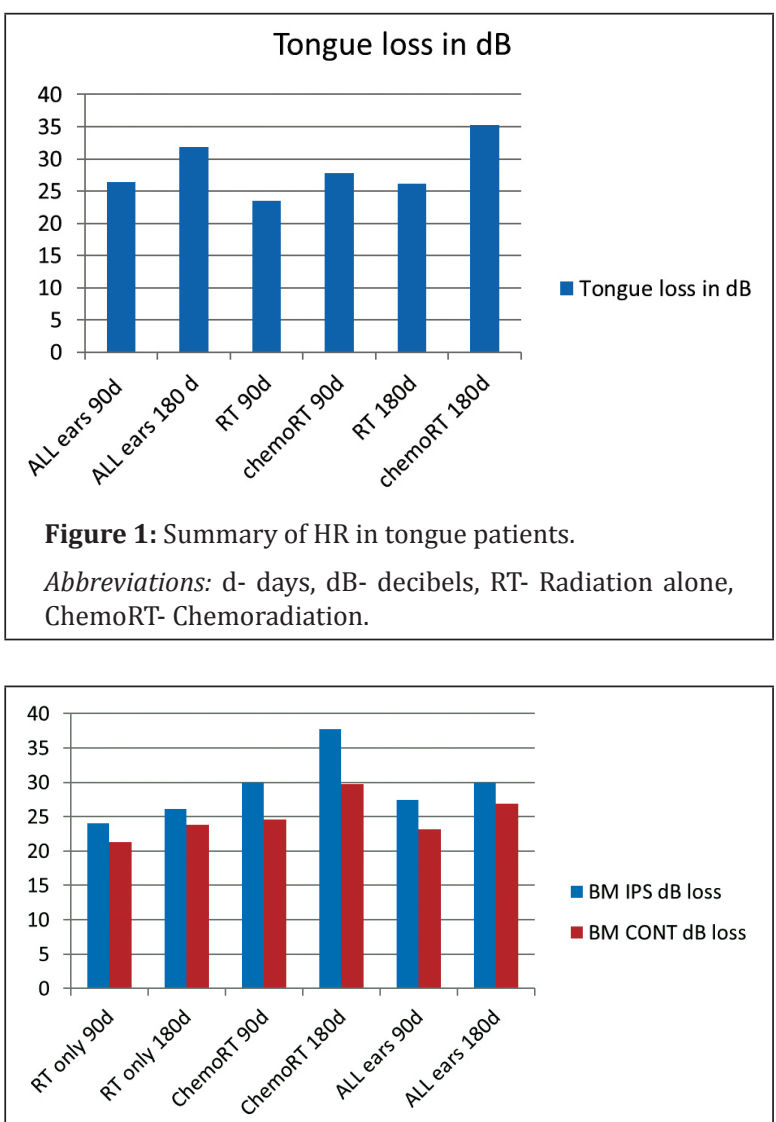

Figure 2: Summary of hearing loss in Buccal mucosa (BM) patients.

Abbreviations: IPS- ipsilateral, CONT-contra lateral, RTRadiation alone, ChemoRT- Chemoradiation.

\section{Discussion}

After careful clinical examination all patients were tested with pure tone audiometry, wherein hearing for air conduction was tested from $250 \mathrm{~Hz}$ to $8 \mathrm{KHz}$ and bone conduction from $500 \mathrm{~Hz}$ to $4000 \mathrm{~Hz}$. Pure tone audiometry is a behavioural quantitative test used to measure hearing threshold levels $(\mathrm{dB})$ of an 
individual enabling to assess the degree and type of hearing loss. It indicates the hearing threshold in $\mathrm{dB}$ that is required to perceive any tone at different or varied frequencies [17]. PTA can be done by any trained audiologist, less time consuming, causing no discomfort to the patients and easy to follow up. It reflects a realistic assessment of hearing as it is interactive with the patient and environment.

In chemoRT for head and neck cancers, cisplatin is the most commonly used drug and is known for its high incidence of SNHL. The ototoxic effects of cisplatin are generally acute in nature and may be observed as early as 3-4 days after administration. Cisplatin initially affects the hearing at higher frequencies and later affects the lower frequencies depending on the duration and length of cycles administered. Its effects are bilateral, irreversible and progressive $[18,19]$. The ototoxic effects of cisplatin may vary amongst various populations in the world. This study was conducted in South India where the temperature and humidity are high and the majority of the treatment took place from March to September when South India experiences hot weather. The ototoxic effects of radiation are not as early as cisplatin and are usually observed after 3 months and gradually progresses from 6 months and reach the plateau at 2 years. Very few continue to have progressive SNHL up to 5 years. The cochlea and inner ear have very small volumes and get contoured in one or two $3 \mathrm{~mm}$ slices making DVHs incalculable. Hence mean doses are mostly available for calculations for are sufficient [20]. The retrochochlear area was neither contoured nor evaluated. The symmetry of the cochlea and ME varies with each patient, basing on neck length, neck rest, flexion and extension of the neck and the serial axial slices on CT scans. Although studies suggest HL with chemoRT with doses as low as 10Gy [21], we observed mild HL with doses as low as 3-5Gy. We also observed that with chemoRT, even though lower radiation doses were delivered to the cochlea and ME (465.18 - 491.50cGy) in tongue VS the larger doses delivered in BM (2992.64 - 3044.14cGy), the hearing loss was statistically similar. This observation is probably because cisplatin has an individual variation in ototoxic effects and other factors like eustachian tube dysfunction leading to $\mathrm{ME}$ effusion, tympanic membrane thickening, ME edema and avascular necrosis of the ME ossicles. RT and ChemoRT with the given doses may lead to mild or moderate HL within 6 months and does not affect the QOL and may be reversed partially with treatment and rehabilitation.

\section{Conclusion}

Shielding the auditory apparatus with a $90^{\circ}$ collimation may help reduce RT dose but its exact role in reducing HR in RT and ChemoRT needs to be verified in larger studies. HL was progressive in both tongue \& BM groups. The present practice of RT doses of $66 \mathrm{GY} \pm$ cisplatin @ $40 \mathrm{mg} / \mathrm{m}^{2}$ leads to mild HR in $60 \%$ patients and moderate HR in $18.4 \%$. The integration of an audiology programme with radiation could assist in early detection and intervention of SNHL \& improve QOL.

\section{Conflict of interest}

Authors declare no conflict of interest.

\section{Acknowledgements}

Radiology Department of Medwin Hospital, and ENT Department of Gandhi Hospital.

\section{References}

[1] Geographic distribution and burden of cancers in India. NICPR. Website: http://cancerindia.org.in/geographicdistribution-burden-cancers-india/

[2] CPAA. We can do it. Website: http://www.cpaaindia.org/ activities/projects.htm\#gutkha

[3] Venkar A. Thank you for smoking: A brief history of tobacco warning labels. Live Mint. Retrieved 5 October 2018.

[4] Pignon JP, le Maitre A, Maillard E, Bourhis J, MACH-NC Collaborative Group. Meta-analysis of chemotherapy in head and neck cancer (MACH-NC): An update on 93 randomised trials and 17,346 patients. Radiother Oncol. 2009; 92(1):414.

[5] Hitchcock YJ, Tward JD, Szabo A, Bentz BG, Shrieve DC. Relative contributions of radiation and cisplatin-based chemotherapy to sensorineural hearing loss in head-andneck cancer patients. Int J Radiat Oncol Biol Phys. 2009; 73 (3):779-788.

[6] Marks LB, Yorke ED, Jackson A, Ten Haken RK, Constine $\mathrm{LS}$, et al. Use of normal tissue complication probability models in the clinic. Int J Radiat Oncol Biol Phys. 2010; 76 (3 Suppl):S10- S19.

[7] Bhandare N, Jackson A, Eisbruch A, Pan CC, Flickinger JC, et al. Radiation therapy and hearing loss. Int J Radiat Oncol Biol Phys. 2010; 76(3 Suppl):S50-S57.

[8] Winquist E, Oliver T, Gilbert R. Postoperative chemoradiotherapy for advanced squamous cell carcinomaof the head and neck: A systematic review with meta-analysis. Head Neck. 2007; 29(1):38-46.

[9] Bernier J, Domenge C, Ozsahin M, Matuszewska K, Lefèbvre $\mathrm{JL}$, et al. Postoperative irradiation with or without concurrent chemotherapy for locally advanced head and neck cancer. $\mathrm{N}$ EngJ Med. 2004; 350(19): 1945-1952. 
[10] Cooper JS, Pajak TF, Forastiere AA, Jacobs J, Campbell BH, et al. Postoperative concurrent radiotherapy and chemotherapy for high risk squamous cell carcinoma of the head and neck. N Eng J Med. 2004; 350(19):1937-1944.

[11] Kapul AA, Zubova EI, Torgaev SN, Drobchik VV. 2017 J. Phys.: Conf. Ser. 881:012010.

[12] Borsanyi S, Blanchard CL, Thorne B. Effect of ionizing radiation on the ear. Ann Otol Rhinol Laryngol. 1962; 70:255-262.

[13] Leach W. Irradiation of the ear. J Laryngol Otol. 1965; $79(10): 870-880$.

[14] Goel HC, Lead P, Naik A. The study of auditory effects after concomitant radiotherapy and chemotherapy in patients with head and neck cancer. Indian J Otol. 2013; 19:136139.

[15] Leonard, L Gunderson, Joel E Tepper. Clinical Radiation Oncology. Third edition. Philadelphia: Elsevier Saunders. 2012.

[16] Wazer DE. Carolyn Freeman. Leonard R. Prosnitz. Principles and Practice of Radiation Oncology. Fifth edition. Philadelphia: Lippincott Williams \& Wilkins. 2008.

[17] Open access guide to audiology \& hearing aids for otolaryngologists. By Maggi Soer, South Africa. www.entdev. uct.ac.za

[18] Kopelman J, Budnick AS, Sessions RB, Kramer MB, Wong GY Ototoxicity of high dose cisplatin by bolus administration in patients with advanced cancers and normal hearing. Laryngoscope. 1988; 98(8 Pt 1):858-864.

[19] Fausti SA, Schechter MA, Rappaport BZ, Frey RH, Mass RE. Early detection of cisplatin ototoxicity, selected case reports. Cancer. 1984; 53(2):224-231.

[20] Pan CC, Eisburch A, Lee JS, Snorrason RM, Ten Haken RK, et al. Prospective study of inner ear radiation dose and hearing loss in head and neck cancer patients. Int J Radiat Oncol Biol Phys. 2005; 61(5):1393-1402.

[21] Bhandare N, Jackson A, Eisbruch A, Pan CC, Flickinger JC, et al. Radiation therapy and hearing loss. Int J RadiatOncolBiol Phys. 2010; 76(3 Suppl): S500-S57. 